\title{
EXPLORING DYADIC RELATIONSHIPS IN VALUE CHAINS USING PHENOMENOLOGICAL CASE STUDY APPROACH
}

\section{Dulekha Kasturiratne ${ }^{1}$}

\section{Introduction}

The research for this paper was conducted over three years from 2003-2006. This paper describes the research methodology used to validate the research question using a case study approach. The first part discusses the various research paradigms around the methodology of phenomenology and the choice for the use of case studies based on interview data. It discusses the design of the data collection instrument leading to how the data were collected and the interviews conducted. The paper concludes with a discussion of the strategies for analysis of the interview data.

\section{Research Question and Background}

The focus of the research is understanding buyer seller relationships in value chains and how value is created in these relationships for competitive advantage. The context of the study is the Sri Lankan tea industry and its cross border exchanges with the UK.

The tea trade has been an important industry for Sri Lanka since its inception in colonial times. With over a century of experience and expertise in production and manufacture, the UK was Sri Lanka's largest and most lucrative tea export market for many years. However, today, Sri Lanka is facing stiff competition from other producer countries such as India, Indonesia and Kenya, the last of which currently supplies about $60 \%$ of the tea needs of the UK (ITC, 2004). Thus Sri Lanka is losing its pioneering and first-mover advantages. Although other export destinations have become more important in Sri Lanka's exports portfolio, the UK is still an important destination in terms of the lessons that can be learnt from the country that is hailed worldwide as the trend-setter in tea. The UK is also the hub for global tea industry activity and acts as an interface where a multitude of international supply chain participants meet. The UK is a sophisticated and mature tea market and there is still a significant segment of tea drinkers in the UK who recognise Sri Lanka (or Ceylon) as a valuable tea producing nation.

In addition to these problems, the Sri Lankan tea industry is facing added pressure from competitors such as Kenya who has surpassed Sri Lanka as the largest exporter. Kenya is a dominant producer of CTC (cut-tear-and-curl) tea which is becoming increasingly popular in many markets. Sri Lanka as a leading supplier of good quality orthodox teas, which command relatively higher prices, is under threat by competitors such as Vietnam and Indonesia offering similar but cheaper teas. Sri Lankan margins are in danger as more and more foreign producers are attracted by premium prices paid for orthodox Ceylon teas.

${ }^{1}$ University of Plymouth, UK and currently in service at School of Business, NSBM Green University Town. Sri Lanka.

Email.dulekha@nsbm.lk; dulekha.kasturiratne@plymouth.ac.uk 
This paper is highlighting the limitations of arms-length adversarial exchanges and identifies the importance of closer buyer-seller relationships as a strategy for more long-term competitive advantage. Thus the main question this research aims to answer through investigating the types of relationships in export-import (buyer-seller) exchanges are:

'What is the role and nature of buyer-seller relationships in export-import exchanges, and what is the impact of the type of relationship on creating value in such business relationships?'

The study uses a conceptual framework for this purpose. This framework was built following an extensive literature review and the preliminary, exploratory data collection stage. It utilises relationship quality measures such as trust, commitment, satisfaction, power, opportunistic behaviour, interaction and social bonding to investigate the types of relationships. This study looks at a more long-term measure of performance and takes a novel perspective with the incorporation of the concept of value-creation for both the buyer and seller.

\section{Research Paradigms}

Of the various types of methodology available in social science research, there are two major approaches to theory development. These are deductive theory testing and inductive theory building (Bonoma, 1985; Parkhe, 1993; Romano, 1989). According to Easterby-Smith et al., (1991), the deductive approach represents the positivist paradigm while the inductive approach represents the phenomenological paradigm.

The positivist paradigm states that theory should come first to be followed by research, and attempts to confirm or refute ideas (hypotheses) through empirical research. This approach uses statistical/quantitative methods of data collection and analysis to verify and confirm theories (Deshpande, 1983).

In the phenomenological paradigm, which is an inductive approach, research takes place before theory. Also, in contrast to the positivist approach, it not only confirms or refutes hypotheses, but also instigates, reformulates and clarifies theories (Nachmias et al., 1992). The extreme position of the inductive approach ends in grounded theory (for a full discussion see Perry 1998, Deshpande 1983) which generates theory from data alone (Glasser et al., 1967), while the extreme end of deductive research assumes that certain events exist and only well-defined relationships between those variables are tested. However, researchers have warned against the dangers and limitations of using either extreme in the inductive/deductive continuum. Perry (1998) states that in practice it is difficult to ignore the theory in one's mind before starting the research process. He also states that both prior theory and theory emerging from the data are involved in the research process in which it is difficult to separate the two, and that it is impossible to go theory-free into a study. Other shortcomings, particularly of grounded theory methods, are that they have been found to be less reliable (Deshpande, 1983), insufficient to portray interviewees stories (Riessman, 1990) and non-straight forward (Richardson, 1994). 
On the other hand, purely deductive research which only involves testing and confirming existing concepts, has been criticised for preventing the development of new and useful theory (Perry, 1998), and for the inability to understand the different 'shades of meaning' behind the statistical formulation which it generates (Deshpande, 1983).

In light of the limitations in the positivist paradigm and in the extremes of both the inductive and deductive approaches, a moderate phenomenological approach was chosen as the most appropriate and preferred methodology for this research to enable answering the above research question.

\section{Phenomenological Case Study Approach}

\section{Phenomenology}

According to Van Manen (1990), phenomenology offers a descriptive, reflective, interpretive, and engaging mode of enquiry from which to derive the essence of an experience. In social science, phenomenology enables the researcher to understand the social world from the perspective of the actors involved and identify with the experience of life events of the stakeholders (Patton, 2002). According to Morse et al., (2002) two major assumptions underlie phenomenology. That is that perceptions present the evidence of the world, not as it is thought to be, but as it is lived; and that human existence is meaningful in a way that people are always conscious of their existence of being in the world. Hence 'being in the world' is a phenomenological phrase acknowledging that people are in their worlds and are understandable only in their contexts. Morse and Richards (2002) also emphasise the phenomenological view that human behaviour occurs in the context of four essentials: relationship to things, people, events and situations.

Phenomenology is divided into three categories by Guba et al., (1994). They are critical theory, constructivism and realism. Perry (1998) presents these ideas in a collective form under the dimensions of deduction/induction, objective/subjective and commensurable/incommensurable, based on studies done by a number of researchers (Guba et al., 1994; Orlikowski et al., 1991; Parkhe, 1993). This is shown in Table 1 below.

Analysis of Table 1 indicates that due to various reasons researchers such as Perry (1998) claim that realism is the preferred paradigm for case study research. Firstly, case study research areas are generally contemporary, such as in the case of inter-organisational relationships and relationship marketing (Boing, 1994). In such cases inductive theory becomes the norm if principles and constructs in the area are not clearly established or are inadequate. Secondly, Perry (1998) says that realism does not suffer from the limitations of relativism (for example the lack of objectivity) as do constructivism and critical theory, because realism is often characterised by researcher objectivity. Thirdly, realism research can be evaluated with measures of reliability and validity, and through review by examiners (Perry, 
1998). He points out that his commensurability is not so evident in constructivism and critical theory research. Hence realism is hailed as the appropriate scientific paradigm for case study research.

Table 1: A three dimensional framework for categorising four specific paradigms

\begin{tabular}{|c|c|c|c|}
\hline \multirow{2}{*}{ Paradigm } & \multicolumn{3}{|c|}{ Dimension } \\
\hline & Deduction/Induction & Objective/Subjective & $\begin{array}{l}\text { Commensurable/ } \\
\text { Incommensurable }\end{array}$ \\
\hline $\begin{array}{l}\text { Positivism } \\
\text { Critical Theory } \\
\text { Constructivism } \\
\text { Realism }\end{array}$ & $\begin{array}{l}\text { Deduction } \\
\text { Induction } \\
\text { Induction } \\
\text { Induction }\end{array}$ & $\begin{array}{c}\text { Objective } \\
\text { Subjective } \\
\text { Subjective } \\
\text { Objective }\end{array}$ & $\begin{array}{c}\text { Commensurable } \\
\text { Commensurable } \\
\text { Incommensurable } \\
\text { Commensurable }\end{array}$ \\
\hline
\end{tabular}

Source: (Perry 1998)

The above discussion of inductive and deductive research with reference to Table 1 might lead the reader to believe that deduction has little place in case study research. This is not necessarily true as case study research does include some deduction based on prior theory (Perry 1998) and most researchers prefer to utilise a mixture of induction and deduction (Eisenhardt, 1991; Parkhe, 1993; Perry, 1998). These researchers say that it is unlikely that any researcher could genuinely separate the two processes of induction and deduction and that both prior theory and theory emerging from the data are always involved. Hence prior theory can have a pivotal function in the design of the case study and analysis of the data, and therefore induction and deduction are linked research approaches (Perry, 1998).

\section{Case Studies}

Case study investigation enables researchers to retain the meaningful characteristics of real life events. While surveys and other methods of quantitative data collection can establish statistically significant links to test research hypotheses, observations and in-depth interviews enable the enhanced understanding of how the hypothesised relationships work in the cases under investigation. In most instances qualitative data from case studies answer 'how?' and 'why?' questions, while quantitative data answer 'who, what, where (or their derivatives of how many and how much?)' questions (Yin, 2003). However certain types of 'what?' questions which are exploratory such as 'what are the ways of making a school effective?' can also be the basis for exploratory case study investigation with the goal being to develop propositions for further investigation (Yin, 1994).

Quantitative methods of analysis are appropriate in certain settings, and much of the 
current relationship marketing theory development relies on survey data to explain the nature of today's buyer-seller relationships (eg. Ganesan, 1994; Heide et al., 1988; Morgan et al., 1994). However, Allport (1961) argues that case study methods permit the type of detailed observation that has the power to reveal various nuances and subtleties of behaviour that other empirical methods might miss; and that in-depth case analyses can help further understanding of complex human relationships (Kazdin, 1980). Some typical uses of case studies include 1) describing a heretofore unstudied situation; 2) exploring a current theory more fully; or 3) supporting, expanding or raising doubts about existing theory (McCutcheon et al., 1993). Lee (1989) emphasises that case study research can be used for each purpose just as effectively as other methodologies that are often viewed as more rigorous or powerful.

An important decision when undertaking case study research is the distinction between single and multiple case study designs. Yin (1994) concludes that a single case study design is appropriate under three circumstances: 1) when the case represents an extreme or unique case; 2) when the case represents a critical case in testing a well formulated theory; and 3) when the case is the revelatory case, which is when the investigator has the opportunity to observe and analyse a phenomenon previously inaccessible to scientific investigation.

The same case study can contain more than a single case. In such instances the study has to use a multiple-case design (Yin, 1994). Evidence from multiple cases is considered more compelling and the study regarded as more robust as a result. At the same time the rationale for single case-designs of being the unusual or rare case, the critical case and the revelatory case, cannot be satisfied by multiple cases (Yin, 1994). In practice, when using multiple-case study designs, four to six cases form a reasonable minimum for a serious research project and the widest accepted range falls between two to four as the minimum and ten, twelve or fifteen as the maximum (Perry, 1998).

Case studies, like face-to-face survey methods, have been criticised for being expensive and time consuming. Some researchers also disapprove of case studies for their lack of 'generalisability'. However, Kennedy (1979) and Yin (1994), although somewhat differently, specify how case study findings can be generalised beyond the specifics of an individual case. Kennedy (1979) argues that the validity of non-statistical inferences can be enhanced when three criteria are met: 1) there is a wide range of attributes across the sample cases, 2) there are many common attributes between the sample case(s) and the general population of interest, and 3) there are few unique attributes within the sample case(s). Yin (1994) however, offers a much different understanding of how case study results can be generalised. He is not keen on trying to justify case studies in terms of a sample being 'representative' of a general population. Instead he says that the investigator's goal is to expand and generalise theories (i.e. analytic generalisation) and not to enumerate frequencies (i.e. statistical generalisation). Thus, Yin's 'analytic generalisation' suggests that the primary role of case studies is to enhance understanding through the development and refinement of theory, and not by providing representative profiles of a particular 
population. In other words, theory, instead of statistical analysis, is the means by which case study results are generalised (Sterns et al., 1998).

\section{Validity and Reliability of Case Studies}

Errors or biases in case study research can be overcome and minimized through following a series of important rules which will increase the validity and reliability of the research. The use of multiple sources of evidence as a process of triangulation encourages convergent lines of enquiry resulting in the conclusions of a case study being more convincing and accurate (Yin, 1994). Perry (1998) suggests having more than one interviewee in case organisations as a desirable form of triangulation. However if the latter is not possible he suggests that additional interviewees from the 'context' of the cases should be included such as consultants, government advisers and industry association people. Other forms of triangulation include the use of more than one interviewer, and use of secondary data by obtaining as many relevant documents as possible such as annual reports, magazine articles etc. (Perry, 1998). Establishing and maintaining a chain of evidence during the research process so that an external observer is able to trace the steps of the research process in either direction, as well as having a draft case study report reviewed by key informants, also enable researchers to increase the validity and reliability of case study research (Yin, 1994). The use of a case study protocol and a case study database are other important practices in this type of research (Yin, 1994). The case study protocol guides the investigator through the research process and contains the procedures and general rules that should be followed. Establishing and maintaining a case study database enables the researcher to organise and document the wealth of data collected in the form of study notes, documents and narratives (Yin, 1994).

\section{Chosen Data Collection Method}

In most cases marketing research methodologies have had their relevance built in developed country settings. Batt (2003), who worked on potato seed marketing chains in Southeast Asia, claims that constructs of marketing relationships used by literature in Western contexts have failed to give satisfactory explanations of the relationship in the countries in which he worked. Matanda (2002) who had worked on a similar research on the horticultural systems in Zimbabwe acknowledges this claim and recommends that an adapted methodology should be devised to better suit the developing country context.

A number of authors have supported the use of case studies in research (Patton, 2002; Yin, 2003), and in the context of agri-business research in particular (Lewin et al., 1997). The review of data collection methods highlighted the phenomenological case study approach as the most appropriate methodology for this research, and one which helps to retain the meaningful characteristic of real life events. This methodology enables the researcher to understand the social world from the perspective of the actors involved and research the contemporary issue of relationships in exporter/importer interactions. This research was conducted through a revision cycle of theory/data/theory where a realistic mixture of deduction and induction was incorporated. Keeping in mind the claims of Batt (2003) and Matanda (2002) above, phenomenological case studies are used in this research to develop more relevant 
constructs and indicators to measure phenomena that are specific to the contexts of this research. The case study approach enabled the preliminary exploratory understanding of the role and nature of buyer/seller relationships as well as the later more detailed understanding of how relationships can achieve competitive advantage.

For the purpose of this research, an individual company is taken as a single case study. Thus, although more than one person may have been interviewed from one company, the overall information obtained from that company is considered as one case study. An in-depth interview technique was utilised and a multiple case study approach was adopted for its persuasive and robust nature. The validity and reliability of the multiple case study design was increased by the process of triangulation. Also a chain of evidence of data collection, a case study protocol and data base were utilised for the purpose of validity and reliability, all of which are described in further detail.

\section{Research procedure}

Data were collected throughout the course of the three years of the project. There were two major data collecting sessions, the first of which was a preliminary, exploratory stage in August 2003 and in December 2004 to February 2005. The second stage was a structured, focused data collection stage with particular emphasis and context given by the preliminary conceptual framework and interview guide. This later data collection took place from July to September 2005 and from November 2005 to February 2006.

\section{The preliminary, exploratory stage}

This stage helped to formulate and reformulate the research questions as well as provide an in-depth overview of the industry and the problems related with it. The foundation to the exploratory stage was laid through the participation in the events of the International Tea Convention held in Colombo, Sri Lanka in August 2003. This was the 15th session of the FAO Inter-Governmental Group (IGG) on Tea, the Tea Convention, exhibition and workshops, all of which were of tremendous interest for this project. Special permission was obtained from the Chairman of the Sri Lankan Tea Board and from the chief organisers of this event in order to participate in the IGG on Tea Conference and for which the Committee for Commodity Problems met annually. Participating in this conference enabled the meeting and networking with many key people in the international tea industry ranging from producers and brokers to exporters and buyers from all over the world. It was an excellent platform from which to obtain an overall and panoramic view of the international tea industry and of the problems in all spheres of the trade.

The exhibition organised under the International Tea Convention was useful in gaining an understanding of the role of indirect stakeholders of the industry such as machinery suppliers (from rollers to tea bagging machines) and flavour suppliers (eg. fruits, herbs). The workshops provided the opportunity for interaction with other direct and indirect stakeholders of the industry such as university students, lecturers and industry researchers as well as Chairmen and Presidents of various Tea Associations, Tea Councils and Tea Boards (both locally and internationally). 
The workshop comprised presentations, discussions and debates. By the end of the International Tea Convention, contact had been already established with many key industry personnel in order to meet and discuss certain issues which arose from this event at a later date. The process of meeting and discussion took three months. These meetings proved extremely useful in the process of networking, where introductions were made to other key industry informants, and facilitated the process of networking with a wide range of key personnel from the entire industry. This enabled a better understanding of certain key issues and concepts that I had come across at the various events of the International Tea Convention.

On my return to the UK, some of the ideas which resulted from the International Tea Convention were used, in conjunction with the knowledge gained from a thorough literature review, to build the first conceptual framework. While in the UK, I met with key industry personnel such as those from the UK Tea Council, UK Tea Association, Twinings and Dilmah Tea. This helped me in obtaining the view from a developed country buyer perspective and the issues related to the tea trade in the UK.

As mentioned before, participation in the events of the International Tea Convention in August 2003 in Sri Lanka laid the foundation to the exploratory stage. The second part of this first stage was completed between December 2004 and February 2005 in Sri Lanka. This session had more focus and emphasis on Sri Lankan exporters of tea to the UK. The idea was to gain as much background knowledge as possible of the relationship aspects of Sri Lankan exporters with their UK importers. Thus, general and some specific questions regarding export relationships were discussed with ten industry Managers and Directors of tea export companies to the UK (see Appendix A for interview guide). These exporters were exporting to other countries besides the UK, and while some were commodity bulk suppliers and some were branded product exporters, there were others who were engaged in the business of exports of both types. As contact had been made with these exporters in the previous visit to Sri Lanka, it was much easier to approach them in this instance, and they in turn made further introductions to other exporters and industry personnel. The interview questions were open-ended and often the discussion which followed simply flowed from the queries that arose from the discussion itself rather than from the questions asked by the interviewer. Hence the actual planned questions asked were few, but the in-depth response that followed as a result of that question helped in obtaining more objective views and connected issues from the interviewee.

Apart from interviews with exporters, data were also gathered and knowledge gained through visits to plantations, producing and manufacturing factories, tea tasting sessions in the principal tea producing regions of Sri Lanka, and the tea auction in the capital Colombo. Discussions with other stakeholders such as the Chairman of the Sri Lanka Tea Board, Director of the Tea Promotions Division of the Sri Lanka Tea Board, brokers, and academics at the Post-Graduate Institute of Management of the University of Colombo, the Tea Research Institute and the Industrial Technology Institute, (ITI, successor to the Ceylon Institute of Scientific 
and Industrial Research - CISIR) also helped in understanding the data and improving the conceptual framework as well as in the process of triangulation. This process enabled to obtain a more holistic and coherent view of the whole industry. The final data collecting stage

The final data collecting stage in Sri Lanka began six months later in July 2005 and ended in September 2005. Knowledge and experience gained from initial data collecting sessions were immensely useful in preparing for this final stage and implementing the data collection plan. The exploratory stage was also useful in adapting and refining questions and methods for the final stage to suit the context of this research. As the research was concentrating on the relationship between exporters of tea to the UK, a list of registered exporters to the UK was obtained from Data One, a company that possesses statistical data and information about exports from Sri Lanka. Information from the Export Development Board was also useful in this respect. Although there are over 200 registered tea exporters in Sri Lanka, there were only 23 exporters on record who had actually exported any tea to the UK in 2004/2005. Out of the 23 exporting companies, 19 companies were interviewed. It was the second time that I was interviewing respondents from some of these companies. This was helpful in finding out any changes that may have occurred during the time lapse as well as for the continuity of the 'story' and clarification of what they may have said in the previous occasions. All of these companies were exporting either bulk tea, value-added tea or both, to the UK as well as other countries. The data triangulation process continued through discussions and interviews with other stakeholders in the industry such as the Chairman of the Sri Lanka Tea Board, Director of The Tea Promotions Division of the Sri Lanka Tea Board, Brokers, Academics at the Post Graduate Institute of Management of the University of Colombo and Directors of the Export Development Board. Further visits to the Tea Board library, Colombo Tea Auction, the Ceylon Chamber of Commerce, tea plantations, factories, warehouses, tea tasting units and the Tea Museum also greatly added to the understanding and richness of the data and knowledge gained. Apart from this, secondary data from books, newspaper articles, official documents, reports and reviews often aided the research process.

Further interviews of the import buyers continued in the UK from November 2005 to February 2006 after the return from Sri Lanka. These buyers are connected across the borders to the supply chain extending to the UK. Some of them were contacted through introductions from the Sri Lankan counterpart and others through network connections in the UK. All six UK buyers who were interviewed were current purchasers of Ceylon tea as well as tea from other tea producing countries such as India, Kenya, Indonesia, Vietnam and China. Much of this tea was purchased in bulk form while some was in the form of value-added tea. Further knowledge was gained through interviewing indirect stakeholders in the industry such as industry experts, Chairman of the UK Tea Council and Tea Association and through visits to tea factories. 


\section{The interviews and interview guide}

Except for one interview which was conducted over the telephone, all other interviews were face-to-face, in-depth interviews which took place in the respective company settings. Appointments for these interviews were obtained in advance over the telephone. A record was kept of the number of times a particular company was contacted, the names of the persons spoken to, and the dates when the telephone conversations took place. The face-to-face nature of the interviews increased the richness and reliability of the data. The physical interaction enabled a better understanding of the information given and the ability to ascertain the meaning of physical gestures and peculiarities in speech. It also helped to build a rapport with the respondent and gain his/her confidence and trust, which resulted in enabling me to ask additional questions and untangle any confusion, which may not have been possible through any other data collecting method. Most interviews lasted about two hours. Effort was taken to interview more than one person from the same company although this was not possible on all occasions. In all cases except one, each person was interviewed individually and separately. In most cases the interviewees were those directly or indirectly in charge of handling the UK/Sri Lanka accounts and therefore were ones with the most knowledge about the relationship. The interviewees consisted of senior buyers/sellers, Managing Directors, Founder-Chairmen, CEOs, Directors and senior managers.

The interviews were aided by an interview guide with 72 open-ended questions. This guide was structured according to the conceptual framework which was built from a thorough review of the literature as well from knowledge gained from the exploratory data collection stage. Thus the interview guide was divided into four main sections:

- Respondent Profile

- The Company

- Export Business Details

- Details of Import Buyer - UK

- General

- Information/Communication

- Relationship \& Relationship Quality

- Creating Value

- Performance/Competitive Advantage

- Product Value

In most cases the interviewee answered the questions at length like a continuing story without the intervention of the interviewer. Therefore, although there were many questions in the interview guide, the lengthy answers that some of the interviewees gave, automatically answered more than one question on the interview guide This gave the information obtained a continuity of past, present and future perspective from the interviewees. Hand written notes were taken at all interviews and most of the interviews were digitally recorded.

Please refer to Figure 1 for the diagrammatic representation of the data collection process and important outcomes at each stage. 


\section{Difficulties faced during data collection in Sri Lanka and UK}

Having had only a limited time period for data collection in Sri Lanka, it was imperative that the appointments were well organised and were as regular as possible. Hence it was fortunate that most of the companies I spoke to were in the precincts of the city of Colombo. However, due to heavy traffic during office hours, travelling from one company to the next was tedious and time consuming. It was often not straightforward to find the right person to talk to over the phone, who would satisfy my requirements of being the person in charge of handling the accounts in the UK (or Sri Lanka). However, when the right person was located it was much easier, in most occasions, to obtain appointments for face-to-face interviews in Sri Lanka than it was in the UK.

This procedure was more informal and open in Sri Lanka than in the UK. In general, appointments for face-to-face interviews were not easily obtained due to the busy schedules of the interviewees who were mostly Senior Managers, CEOs and Senior Buyers. Appointments that were made beforehand were sometimes cancelled or postponed at the last minute. A particular complication faced in Sri Lanka was that appointments were limited to Mondays, Thursdays and Fridays as the Tea Auction was held on the other two days of the week, and most often the interviewees would attend the auction at some time on these two days. All the interviews (except for one telephone interview) took place in the respective company settings. This was ideal in that the interviewee was operating in his/her usual work environment and was more relaxed and involved in the questions asked.

Figure 1: Data collection process and outcomes at each stage

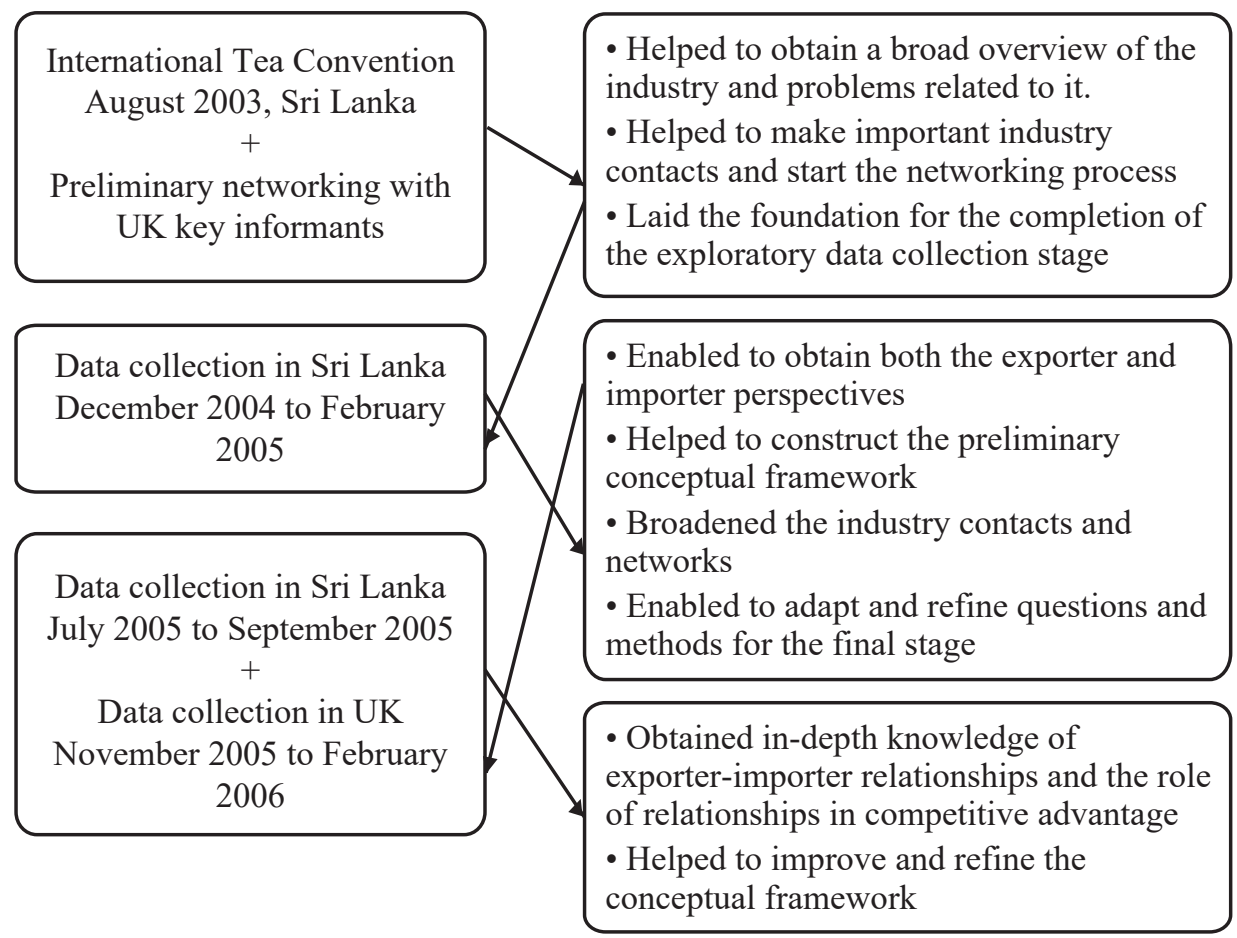


Many unforeseen but favourable opportunities arose due to the interviews taking place in the company settings such as enabling me to observe the typical work environment as well as having easy access to other employees in the company. However, on some occasions, the work environment also posed a few disturbances and interruptions to the continuity of the interview with ringing telephones and various people popping in to the office. On some occasions in Sri Lanka, the interviewee's office was extended and being shared by other employees who were tasting and cataloguing teas for the auction. Although this was an ideal environment in many ways such as observation, it was not perfectly suited for the purpose of a recorded interview.

In hindsight it would have been more appropriate to meet certain key respondents before/after others in order to increase 'sequentiality' of the information gathered. In other words, the ideal situation would have been to meet a few respondents in Sri Lanka, then in the UK and then back to Sri Lanka. However, this was not always possible due to budget and time constraints.

There was one instance in Sri Lanka when the interviewee refused to be recorded, and there were a minority of respondents who spoke certain words/sentences 'off the record'. Approach to Analysis

Some interviews from the preliminary, exploratory stage and most interviews from the final data collection stage were digitally recorded and handwritten notes were taken at all the interviews. A software (SVR-M90x) was used to upload the digital information to the computer. This software was pivotal in maintaining and storing voice data in organised electronic files. The data from the exploratory stage were in the form of detailed notes from the outcomes of each interview. All the interviews from the final stage were transcribed for within-case and cross-case analysis. Interviews of other key industry respondents and secondary information were useful in data triangulation. This additional information was helpful in understanding the context and added meaning and depth to the overall information obtained. A diary of records and a database of information were also maintained for ease of analysis.

The detailed notes from the exploratory stage were scanned for any emerging trends and for information about relationships and aspects of the relationship such as level of information/communication, joint involvement in the product, decision making and aspects of power and balance in the relationship. This stage was more general and was immensely useful in obtaining an overview of the industry as well as a prerequisite stage for adapting and refining questions and methods for the final stage. An important outcome of this stage was the preliminary conceptual framework which was built with key ideas emerging from the exploratory stage and from the literature review.

In the final data collecting stage, from the 25 companies interviewed, interviews from 22 companies were utilised. Three were not included due to limited information given and were considered inadequate for rigorous analysis. The information obtained from the interviews was categorised into several groups according to the key concepts in the preliminary conceptual framework. These included the level of 
information/communication between the buyer and seller, relationship quality and other relationship aspects, value creation in the relationship, and measures of relationship performance. This categorisation of information was a useful process of managing the vast amount of information obtained through data collection. The cases were analysed both within-case and across cases.

Re-listening to the interviews and re-reading the transcripts were important steps in the analysis process. While the application of keyword search tools on the electronic transcript files was useful, manual annotations and memos were also taken along the way. Furthermore, words, phrases and ideas were highlighted and labelled, and a trail of links was followed through the data. From this process, any general trends emerging from Sri Lanka and the UK were noted. All cases were compared and contrasted against one another on key points and concepts, and special cases were analysed in further depth for their uniqueness and emergent new ideas. Simultaneously, evidence from literature was utilised to support or contradict what was identified. Due to the vast amount of data gathered, eleven cases were chosen for further examination and discussion. This process of data reduction was required in order to present a practical yet meaningful analysis. The eleven cases were chosen as those that were most representative of all the cases in general as well as those that were unique and distinctive. The analysis and interpretation of the interviews of the eleven cases reflected data obtained from the remaining cases.

\section{The use of key concepts for analysis}

This section discusses the key concepts that emerged from the analysis of the cases.

Product value: the product value lies outside the intrinsic relationship characteristics such as information/communication, relationship quality and creating value. The respondents were asked to identify the value of the products they are exporting/importing. Thus the idea was to distinguish if the products were in bulk form, branded, or in the case of exporting firms, if they were contract packers. This helped in identifying the link between the value of the product and the type of relationships maintained, and whether there was an impact of one over the other.

Information/communication: here the respondents were asked to comment on the level, content, medium and frequency of communication. This helped to identify who the immediate contacts are from the two countries, the ease of reaching them, their efficiency in responding to queries and most importantly the content of the communication. For example, it was important to understand if the information being communicated only pertained to product orders, deliveries and payment, or whether it also contained other information such as consumer/market trends, competitor information, new product development, training schemes etc. This was an important step in identifying the strength of the connection between the exporter and importer and determining whether or not they are functioning in isolation of each other.

Relationship quality: the respondents were asked questions to understand the nature, type and quality of the relationship with their counterparts in the other country. This consisted 
information about contracts/agreements, length of relationship, flexibility, level of trust, commitment, interaction, conflict resolution, trainee exchange programmes, interdependence, expectation of continuity etc. This helped to understand the basis of the relationship, its current situation and future direction. It also helped in identifying the various ways in which relationship quality is linked with the concept of creating value within the relationship.

Creating value: this research aims to increase the understanding of the complex concept of value. Here the focus is on the value that is created within the relationship which is beneficial to both the buyer and the seller. Thus the created value is an outcome of the characteristics of the relationship. The respondents were encouraged to talk about how they thought the relationship may have been helpful in creating new opportunities or benefits.

Relationship performance: there are two important things to note here. The first is that performance was measured in terms of the relationship which is a more long-term measure of performance. The second is that the respondents were given the freedom to discuss relationship performance in their own vocabulary and as they perceived it, without restricting them to specific research/academic vocabulary or thoughts. This gave the respondents a chance to think about the relationships they maintained with their counterparts and express their thoughts on the costs or benefits of maintaining these relationships. What is interesting is that attributes which were used to describe some relationship characteristics and aspects of value creation were also used by the respondents to describe relationship performance. Thus, attributes used to describe one dimension were revealing information about another. For example, while the level of joint participation can describe relationship quality, it can also describe value creation in the relationship and be used as a measure of relationship performance.

These key concepts are diagrammatically and relationally represented in Figure 2.

Figure 2: Framework of key concepts

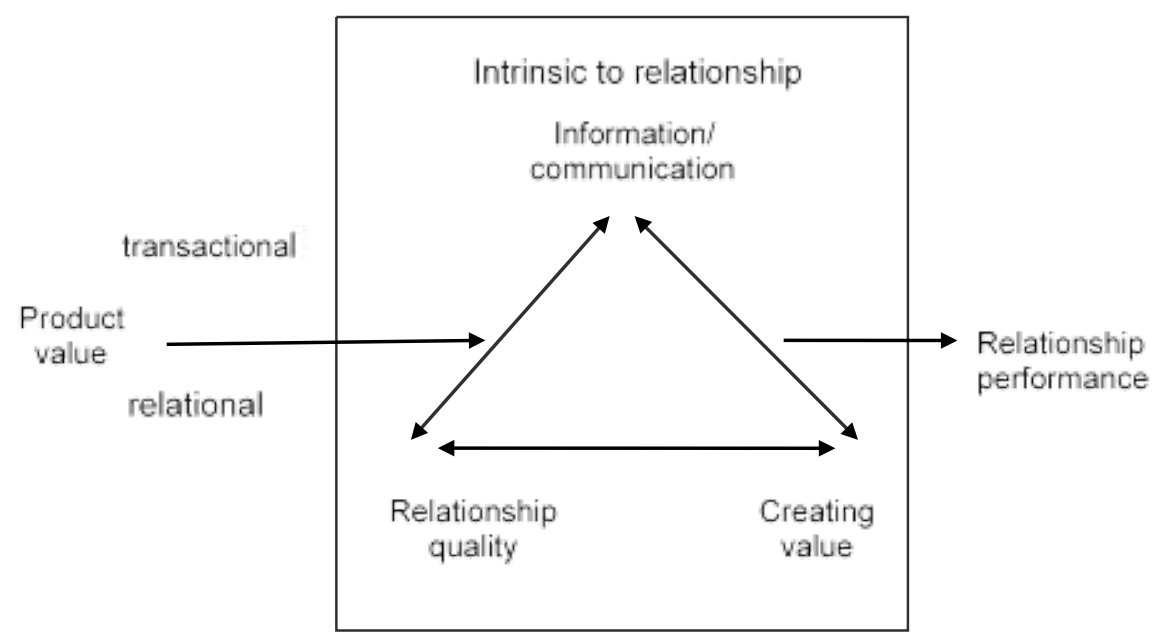




\section{Conclusion}

This paper sets out the details and justification of the most suitable methodological approach chosen for fulfilling the requirements of the research question. Details of the phenomenological case study approach using face-to-face interview data were discussed along with the emergence of key concepts enabling furthering the analysis of the data. The analysis of the data using this case study approach was found to be ideal in identifying sensitive data which were key in characterising the life-cycle of the supplier-buyer relationship and the value it can create. This study further reinforced the phenomenological case study approach as a stand-alone, valid, and significant research tool. It assists in understanding and theorising the value chain, thereby adding to new knowledge.

\section{References}

Allport, G.W. (1961). Patterns in Growth and Personality: Holt, Rinehart and Winston, New York

Batt, P.J. (2003). Building Close and Long-Lasting relationships with Focal Customers: An Empirical Study of Seed Potato Purchasing by Filipino Potato Farmers.

Unpublished Ph.D. Thesis. Curtin University of Technology, Perth, Western Australia ITC. (2004b). International Tea Committee, Annual Report

Boing, H. (1994). The Role of a Salesperson Within a Long Term Buyer-Supplier Relationship in the Industrial Market. Paper presented at the Relationship Marketing, Theory, Methods and Applications, Emory University, Atlanta.

Bonoma, T.V. (1985). Case Research in Marketing: Opportunities, Problems, and a Process. Journal of Marketing Research, 22(May): 199-208.

Deshpande, R. (1983). Paradigms Lost: On Theory and Method in Research and Marketing. Journal of Marketing, 47: 101-110.

Easterby-Smith, M., Thorpe, R. \& Lowe, A. (1991). Management Research an Introduction: Sage, London.

Eisenhardt, K.M. (1991). Better Stories and Better Constructs: The Case for Rigor and Compararive Logic. Academy of Management Review, 16(3): 620-627

Ganesan, S. (1994). Determinants of Long-Term Orientation in Buyer-Seller Relationships. Journal of Marketing, 58(April): 1-19.

Glasser, B.G. \& Strauss, A.L. (1967). The Discovery of Grounded Theory: Strategies for Qualitative Research: Aldine Publishing Company. 
Guba, E.G. \& Lincoln, Y.S. (1994). Competing Paradigms in Qualitative Research. In N. K. Senzin \& Y. S. Lincoln (Eds.), Handbook of Qualitative Research: Sage, Thousand Oaks.

Heide, J. \& John, G. (1988). The Role of Dependence Balancing in Safeguarding Transaction-Specific Assets in Conventional Channels. Journal of Marketing, 52(January): 20-35.

Kennedy, M.M. (1979). Generalizing from Single Case studies. Evaluation Quarterly, 3: 661-678.

Lewin, J., E. \& Johnston, W.J. (1997). Relationship Marketing Theory in Practice: A Case Study. Journal of Business Research, 39: 23-31.

Matanda, M.L.J. (2002). Market Orientation, Business-to-Business Relationships, Customer Satisfaction, Business and Channel Performance in Horticultural Markets. Unpublished Ph.D. Department of Marketing, Faculty of Business Economics, Monash University, Australia.

McCutcheon, D.M. \& Meredith, J., R. (1993). Conducting Case Study Research in Operations Management. Journal of Operations Management, 11(September): 239-256

Morgan, R.M. \& Hunt, S.D. (1994). The Commitment-Trust Theory of Relationship Marketing. Journal of Marketing, 58(3): 20-38

Morse, J.M. \& Richards, L. (2002). Readme First for a User's Guide to Qualitative Methods: Thousand Oaks: Sage.

Nachmias, C. \& Nachmias, D. (1992). Research Methods in the Social Sciences (4th ed.): St Matins Press.

Orlikowski, W. \& Baroudi, J. (1991). Studying Information Technology in Organisations: Research Approaches and Assumptions. Information Systems Research, 2(1): 1-28.

Parkhe, A. (1993). Messy's research methodological predispositions and theory development in international joint ventures. Academy of Management Review, 18(2): 227-268.

Patton, M.Q. (2002). Qualitative Research and Evaluation Methods: Sage Publications, California.

Perry, C. (1998). Process of a Case Study Methodology for Postgraduate Research in Marketing. European Journal of Marketing, 32(9/10): 785-802.

Richardson, L. (1994). Writing: A Method of Enquiry. In N. K. Denzin \& Y. S. Lincoln (Eds.), Handbook of Qualitative Research: Thousand Oaks, CA: Sage. 
Riessman, C.K. (1990). Divorce Talk: Women and Men Make Sense of Personal Relationships: New Brunswick, NJ: Rutgers University Press.

Romano, C. (1989). Research Strategies for Small Business: A Case Study. International Small Business Journal, 7(4): 35-43.

Sterns, J.A., Schweikhardt, D.B. \& Peterson, H.C. (1998). Using Case Studies as an Approach for Conducting Agribusiness Research. International Food and Agribusiness Management Review, 1(3): 311-327.

Van Manen, M. (1990). Researching Lived Experience: Human Science from an Action Sensitive Pedagogy: London, ON: Althouse.

Yin, R.K. (1994). Case Study Research: Design and Methods (2 ed.): Sage Publications, Thousand Oaks, California.

Yin, R.K. (2003). Case Study Research Design and Methods (3 ed.). California: Sage Publications 